\title{
Energy Band Gap under the Effect of Temperature in Lead Sulfide (PbS)
}

\author{
Dipak Raj Adhikari ${ }^{1}$, S.K.Adhikari ${ }^{2}$ and Hari Prasad Lamichhane ${ }^{3}$ \\ ${ }^{1}$ Department of Physics, Amrit Science Campus, Tribhuvan University \\ ${ }^{2}$ Department of Physics, Birendra Multiple Campus, Tribhuvan University \\ ${ }^{3}$ Central Department of Physics, Tribhuvan University
}

Nepal

\begin{abstract}
In the present paper, the energy band gaps with temperature have been studied in lead sulfide (PbS). The energy band gap is a linear function of temperature. The values of the energy band gap in different temperature are calculated. The calculated values are a close agreement with the experimental results.
\end{abstract}

Keywords: Energy band gap, Lead sulfide.

\section{INTRODUCTION}

In most semiconductors the electron-phonon interactions lead to an increase the energy band gap with decrease in temperature. In lead sulfide the reverse effect occurred due to harmonic and anhormonic contribution of electron - phonon interaction. The lead sulfide $(\mathrm{PbS})$ has unique structural and electronic properties. It has wide technological applications and uses to fabricate in various optoelectronic, spintronic, thermo- electronic devices, nanoscience, nanotechnology [1-9]. The energy band gap decrease with decrease in temperature [10-14]. The larger diameter of lead sulfide made to decrease the energy band gap with decrease in temperature. The theoretical and experimental studies have been performed on their structural and electronic properties [1524].Those properties have been studied in terms of energy band gap and harmonic and anhormonic contribution of electronphonon interaction. The energy band gap is the function of temperature [17-25]. The calculated values are close agreement with experimental results.

\section{THEORETICAL METHODOLOGY}

In most of the semiconductors the electron-phonon interactions lead to an increase the energy band gap with decrease in temperature. In lead sulfide have occurred the reverse effect due to harmonic and anhormonic contribution of electron - phonon interaction. The lead sulfide $(\mathrm{PbS})$ is narrow band gap semiconductor. The energy band gap is the function of temperature [21-22]. The crystal structure of lead sulfide is $\mathrm{NaCl}$ (B1) type. It is shown in fig 1.The coordination number of lead sulfide is 6 . The electronic and structural properties were studied in terms of energy band gap with temperature [20-23]. Various experimental studies have been found the lead sulfide exhibit strongly anharmonic lattice dynamics [24].The Coulomb interaction and short range two-body interactions between lead sulfide is given by

$\mathrm{U}_{\mathrm{ij}}=\frac{Q_{i} Q_{j}}{R_{i j}}+X e^{\frac{-R_{i j}}{\rho}}-\frac{D_{6}}{R_{i j}^{6}}$

In equation (1), The first term describe the long range Coulomb interaction between two charges .The second term indicates the repulsive potential. Third term represent the dipole- dipole interaction

The total energy band gap due to harmonic and anharmonic contribution of electron- phonon interaction is given by $\frac{\partial E_{g}}{\partial T}=\left(\frac{\partial E_{g}}{\partial T}\right)$ harmonic $+\left(\frac{\partial E_{g}}{\partial T}\right)$ anharmonic

In eq.(2) first term be the band gap due to harmonic and second term energy band gap due to anharmonic term

The energy gap is related with temperature and lattice parameter by following relation 
International Journal of Advances in Scientific Research and Engineering (ijasre), Vol 5 (6), June-2019

$$
\left[\frac{\partial E g}{\partial T}\right]_{\text {LATTICE }}=\left(\frac{\partial E g}{\partial a}\right)\left(\frac{\partial a}{\partial T}\right)
$$

The forbidden width is a linear function of temperature [31-33] then

$E_{g}(T)=E_{g}(0)+\frac{\partial E_{g}}{\partial T} \mathrm{~T}$

$E_{g}(0)$ be the energy at absolute zero

$\frac{\partial E_{g}}{\partial T} \quad$ be the slope from the graph

The crystal structure and the variation of energy gap with temperature are shown in Fig 1 and 2 respectively. The energy band gap is the linear function of temperature. The values of energy band gap in different temperature are calculated. The calculated values are shown in table 1 . Finally our calculated values are close agreement with the experimental results.

\section{RESULTS AND DISCUSSION}

In this method, energy band gap with temperature have been studied and calculated in lead sulfide $(\mathrm{PbS})$ under the effect of temperature. The values of energy band gap in different temperature are shown in table 1 . The variations of energy band gap with temperature are predicted in Fig 2.The larger diameter of lead sulfide made to decrease the energy gap with decrease in temperature under the effect of electron- phonon interaction. Our calculated parameters are close agreement with experimental result.

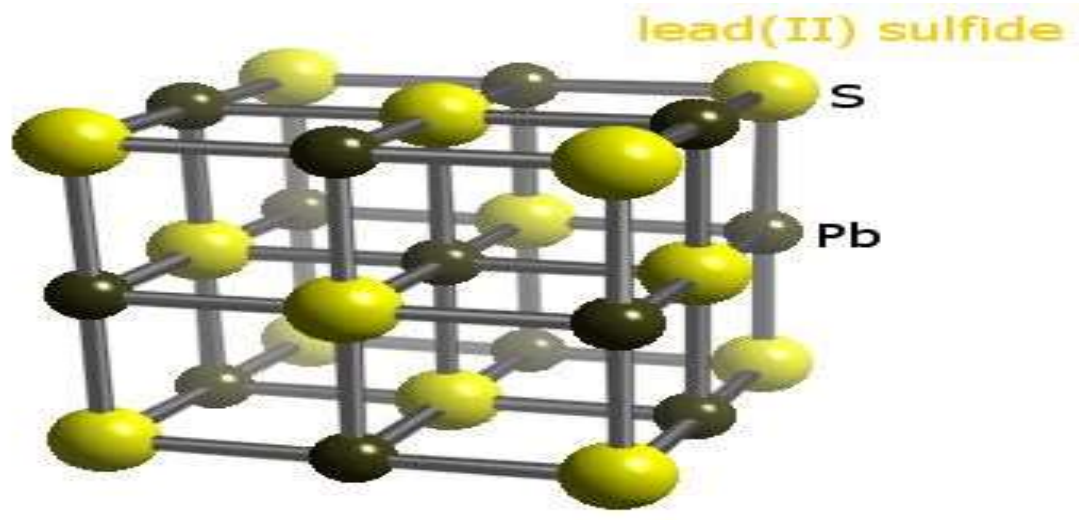

Fig 1 Crystal structure of lead sulfide (PbS)

Table 1. The values of energy band gap with temperature in lead sulfide (PbS)

\begin{tabular}{|c|c|c|}
\hline $\begin{array}{c}\text { Temperature } \\
(\mathbf{K})\end{array}$ & $\begin{array}{c}\text { Energy band gap } \\
\text { Exp.[16] }\end{array}$ & Energy band gap Calc. \\
\hline 0 & 1.083 & 1.083 \\
\hline 50 & 1.085 & 1.088 \\
\hline 100 & 1.092 & 1.091 \\
\hline 150 & 1.096 & 1.098 \\
\hline 200 & 1.102 & 1.103 \\
\hline 250 & 1.105 & 1.108 \\
\hline 300 & 1.110 & 1.113 \\
\hline
\end{tabular}




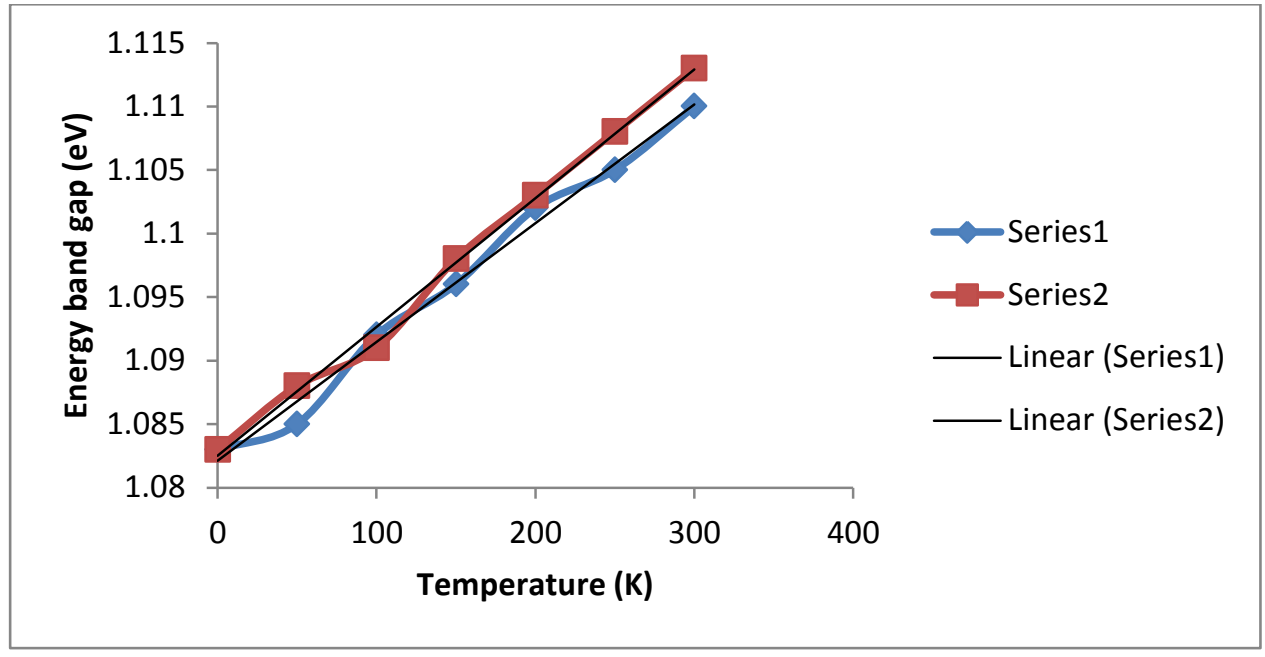

Fig.2. Energy band gap with temperature for $\mathrm{PbS}$

\section{CONCLUSION}

In lead sulfide the reverse effect of semiconductor have occurred due to harmonic and anhormonic contribution of electron - phonon interaction. It is narrow band gap semiconductor. The energy band gap is the linear function of temperature. The calculated values of energy band gap are close agreement with the experimental result.

\section{REFERENCES}

[1] V. I. Smelyansky and J. S. Tse, , 1995 , Physical Review B, vol. 52, no. 7, pp. 4658-4661

[2] A. Paul and G. Klimeck, 2011, Applied Physics Letters, vol. 98, no. 21, Article ID 212105

[3] E. A. Albanesi, C. M. I. Okoye, C. O. Rodriguez et al., 2000, Physical Review B: Condensed Matter and Materials Physics, vol. 61 , no. 24 , pp. $16589-16595$

[4] A. Grzechnik and K. Friese, 2010, Journal of Physics Condensed Matter, vol. 22, no. 9, Article ID 095402

[5] G. Rousse, S. Klotz, A. M. Saitta et al., 2005, Physical Review B, vol. 71, no. 22, Article ID 224116

[6] S. V. Ovsyannikov, V. V. Shchennikov, A. Y. Manakov et al., 2007, Physica Status Solidi (B) Basic Research, vol. 244, no. 1, pp. 279-284

[7] B. K. Panda and H. C. Padhi, 1991, Physica Status Solidi B, vol. 166, no. 2, pp. 519- 523

[8] T. Chattopadhyay, A. Werner, H. G. von Schnering, and J. Pannetier, 1984, Revue de Physique Appliquee', vol. 19, no. 9, pp. $807-813$

[9] T. Chattopadhyay, H. G. von Schnering, W. A. Grosshans, and W. B. Holzapfel, 1986, Physica B+C, vol. 139-140, pp. 356360

[10] W.Paul,R.V.Jones, 1953,Proc.Phys.Soc.B 66,194

[11] T.G.M.Baleva,G.Lashkarev, 1990,J.Phys.Condens Matter 1, 2935

[12] R.A.Laff, 1965,J.Appl.Phys.36, 3324

[13] Q.Dai,Y.Zhang,Y.Wang,M.Z.Hu,B.Zou,Y.Wang,W.W.Yu Langmuir, 2010, 26,11435

[14] T Schwarzl,E.Kaufann,G.Springholz,K.Koike,T.Hotei,M.Yuno,W.Heiss, 2008,Phys.Rev.B 78, 165320

[15] X. Peng, L. Manna, W. Yang, J. Wickham, E. Scher, A. Kadavanich, and A. P. Alivisatos, 2000, Nature 404, 59-61

[16]Z. A. Peng and X. Peng, 2001,J. Am. Chem. Soc. 123, 183-184 
[17] R. D. Schaller and V. I. Klimov, 2004, Phys. Rev. Lett. 92, 186601

[18] R. J. Ellingson, M. C. Beard, J. C. Johnson, P. Yu, O. I. Micic, A. J. Nozik, A. Shabaev, and A. L. Efros, 2005, Nano Lett. 5, 865-871

[19] A. Sadao, Properties of Group-IV, III-V and II-VI Semiconductors (Wiley, New York, 2005)

[ 20] A. P. Alivisatos, 1996, Science 271, 933-937

[21] O. Madelung, U. Rössler, and M. Schulz, Landolt-Börnstein III/41C: NonTetrahedrally Bonded Elements and Binary Compounds I (Springer-Verlag, Berlin, Germany, 1998)

[22] Y. Bencherif, A. Boukra, A. Zaoui, and M. Ferhat, 2011, Materials Chemistry and Physics, vol. 126, no. 3, pp. 707-710

[23] R. Ahuja, 2003, Physica Status Solidi (B) Basic Research, vol. 235, no. 2, pp. 341-347

[24] K. Hummer, A. Gruneis, and G. Kresse, 2007, Physical Review B: Condensed Matter and Materials Physics, vol. 75, no. 19, Article ID 19521

[25] P.Dey,J.Paul, J.Bylsma, D.Karaiskaj,J.M.Luther,M.C.Bead,A.H.Romero, 2013,Solid State Communication 165,49-54

[26] Y. Z. Pei, X. Y. Shi, A. LaLonde, H. Wang, L. D. Chen, and G. J. Snyder, 2011, Nature 473, 66

[27] Z. M. Gibbs, H. Kim, H. Wang, R. L. White, F. Drymiotis, M. Kaviany, and G. Jeffrey Snyder, 2013, Applied Physics Letters 103

[28] J. P. Heremans, V. Jovovic, E. S. Toberer, A. Saramat, K. Kurosaki, A. Charoenphakdee, S. Yamanaka, and G. J. Snyder, 2008,Science 321,554

[29] Z. T. Tian, J. Garg, K. Esfarjani, T. Shiga, J. Shiomi, and G. Chen, 2012, Phys. Rev. B 85

[30] E. S. Bozin, C. D. Malliakas, P. Souvatzis, T. Proffen, N. A. Spaldin, M. G. Kanatzidis, and S. J. L. Billinge, 2010, Science 330,1660

[31] A. J. Miller, G. A. Saunders, and Y. K. Yogurtcu, 1981, J. Phys. C 14, 1569

[32] R. Dornhaus, G. Nimtz, and B. Schlicht, 1983,Springer Tr Mod Phys 98, R-5

[33] O. Madelung, M. Schultz, and H. Weiss, Group III: Semiconductors (Springer, Berlin, 1982) 